\title{
Reduction of Vertical Transmission of HIV Through the Use of Mother Buddies in Plateau and Kaduna States of Nigeria
}

\author{
Christian Ogoegbunem Isichei ${ }^{1,4}$, David Deakin ${ }^{2}$, Danladi Musa $^{3}$, Paul Mershak ${ }^{3}$, \\ Caroline Onwuezobe ${ }^{4}$, Martha Nyam ${ }^{4}$, Jane Nwoke ${ }^{4}$ \\ ${ }^{1}$ Department of Chemical Pathology, Faculty of Medical Sciences, University of Jos, Jos, Nigeria \\ ${ }^{2}$ Tearfund, London, United Kingdom \\ ${ }^{3}$ Tearfund, Jos, Nigeria \\ ${ }^{4}$ Faith Alive Foundation, Jos, Nigeria
}

Email address:

Christian_isichei@yahoo.com (C. O. Isichei)

\section{To cite this article:}

Christian Ogoegbunem Isichei, David Deakin, Danladi Musa, Paul Mershak, Caroline Onwuezobe, Martha Nyam, Jane Nwoke. Reduction of Vertical Transmission of HIV Through the Use of Mother Buddies in Plateau and Kaduna States of Nigeria. American Journal of Clinical and Experimental Medicine. Vol. 3, No. 5, 2015, pp. 200-206. doi: 10.11648/j.ajcem.20150305.11

\begin{abstract}
Background. Nigeria has the second largest number of People Living with HIV/AIDS (PLWHA) in the world. In 2009 , of 27,870 Nigerian infants exposed to HIV, only 15,785 were on antiretroviral prophylaxis and $32 \%$ of the HIV-positive women received ARVs.It is now possible to reduce the rate of HIV transmission from HIV-infected mothers to their infants to less than 2\%. While achievements in Prevention of Parent-To-Child Transmission (PPTCT) of HIV programmes or Prevention of Mother-To-Child Transmission (PMTCT) of HIV programmes are dramatic, these programmes need to be further improved and sustained. Methods. We developed "mother buddies" to improve access to PPTCT services in three underserved local government areas with 15 communities of Plateau and Kaduna States of Northern Nigeria in keeping with Dzama and Deakin's pilot study in Malawi. Mother buddies are HIV-positive mothers who use Mobile Interactions bringing Hope (Mihope) phones to provide one-to-one life-saving support to vulnerable pregnant women and their families during pregnancy and for 6 months after child birth. The programme was implemented from October 2013 to March 2015.Life-saving support included information on HIV, PPTCT, family planning, Sexually Transmitted Infections, increasing male partners involvement and Antiretroviral(ARVs). Educational topics included the importance of attending antenatal clinic (ANC) before delivery, healthy diet patterns, partner testing for HIV, syphilis testing and malaria prophylaxis. Results. All education and support was accomplished on a one-on-one basis, thereby increasing knowledge, changing attitudes and practice. It also promoted health seeking behavior that improved access and uptake for PMTCT services in these rural areas. Of the 97 HIV--positive women, 64 gave birth safely and the babies received PPTCT/PMTCT Interventions. Forty-seven babies tested negative to two DNA PCR tests at 6 weeks after delivery and 6 weeks after cessation of breast milk feeding, while 17 babies tested negative to first DNA PCR, and were awaiting second DNA PCR after 6 weeks of cessation of breast feeding at the time of this analysis. Conclusions. Despite logistical challenges, security concerns and project design limitations, "Mother buddies" demonstrated the capacity to increase access to PPTCT/PMTCT services in hard to reach and underserved communities with great impact/outcomes.
\end{abstract}

Keywords: Antenatal, PPTCT/PMTCT, HIV, Mother Buddies, PLWHA, ARVs, IMPACT, Mihope Phones

\section{Introduction}

Tearfund is a United Kingdom-based Christian non-profit organization that contributes to a global effort to eliminate mother-to-child transmission of HIV and has great presence in Nigeria. Most children living with HIV acquire the infection through transmission from their mothers who may be infected by their partners/spouses during pregnancy and lactation hence the focus on including male sexual partners in all programmes.It is however noted that there are other means of infection other than directly through spouses during sexual intercourse. Contact tracing is usually very helpful. In the absence of an effective intervention, the risk of vertical HIV transmission is $20-45 \%$ (WHO 2010). This transmission rate can be reduced to below $2 \%$ with early HIV detection and rapid initiation of Highly Active Antiretroviral Therapy 
(HAART). Primary HIV prevention is important in ultimately controlling the epidemic of HIV infection in women and children. Primary prevention is achieved by education and universal testing of both men and women for HIV.

Early diagnosis of HIV and treatment of HIV-infected men and women with HAART can reduce HIV transmission to sexual partners and is associated with better antenatal care, delivery care, and appropriate infant feeding.

Achieving the Millennium Development Goals (MDGs) for Maternal and Child Health $(\mathrm{MCH})$ and overcoming major communicable diseases requires effective access to HIV PPTCT services, especially in underserved communities. The provision of antiretroviral (ARV) drugs, counseling and psychological support to help mothers and fathers safeguard their infants against the virus are key components of prevention of parent-to-child transmission (PPTCT) programmes-one of the aims of the IMproving Parent And Child ouTcome(IMPACT) programme in Nigeria and which is aggressively being pursued by in country team. This will ensure that children in hard to reach areas are born free of HIV.Tearfund's approach to PPTCT is church-based and emphasizes the importance of male involvement. As a faithbased organization, it also emphasizes the responsibility of men and women to partner together to protect themselves from HIV infection and prevent its transmission. This article describes efforts to promote PPTCT through the use of "Mother buddies". Mother buddies (MBs) are mothers themselves who are also HIV-positive and trained community workers empowered with an innovative mobile phone system, MiHope. Their role is to work with vulnerable mothers to reduce child and maternal morbidity and mortality as well as assisting in the goal of zero HIV-MTCT through education, support, and encouraging them to participate in the component parts of the IMPACT programme.This programme focuses on parental health, planning for pregnancy, and antenatal care, delivery and postnatal care, together with care for infants and young children through health care promotion run by Tearfund's community-based Christian organizational partners like Faith Alive Foundation (FAF).

Their roles seem similar to that of Trained Birth Attendants (TBAs) if not more as they Mother Buddies are also HIV positive.

\section{Methods}

\subsection{Study Design}

This study evaluates the efficacy of implementing a "Mother buddies" intervention within the IMPACT programme in two Nigerian States of Plateau (P) and Kaduna (K). As shown in Figure 1, IMPACT uses a comprehensive strategy to reduce HIV transmission. The work is based on the pilot work carried out by Tearfund's IMPACT programme in Malawi and now in Nigeria and the engagement of mother buddies using Mihope phones in hard to reach rural areas. The MiHope provided communication, information, client services and data capture. It helped a lot with clinic visit reminders both directly from MBs and as SMS reminders from clients.

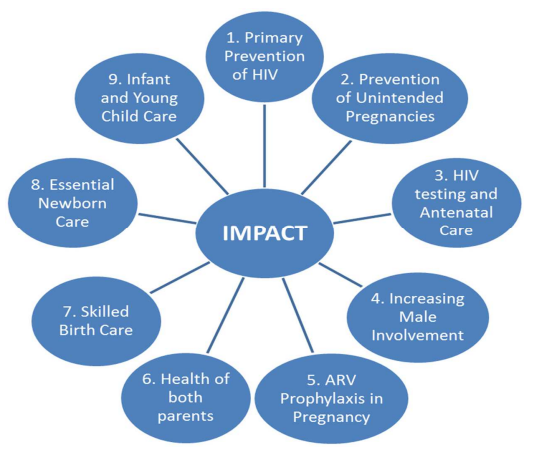

Figure 1. Overview of IMPACT programmes-a comprehensive approach of PPTCT/PMTCT to reduce Maternal and Child Health Morbidity and Mortality.

\subsection{Mother Buddies Intervention}

Table 1. Focused Antenatal Care Model.

\begin{tabular}{llllllll}
\hline \multicolumn{2}{l}{ Pregnancy-9 months } & & & Birth & \multicolumn{2}{l}{$\begin{array}{l}\text { Post birth to 6 } \\
\text { months }\end{array}$} \\
\hline $\begin{array}{l}\text { ANC } \\
\text { Visits }\end{array}$ & 1 & 2 & 3 & 4 & & $\begin{array}{l}\text { Further } \\
\text { visits }\end{array}$ & clinic \\
Weeks & $8-12$ & $24-26$ & 32 & $36-38$ & & & \\
\hline
\end{tabular}

As part of the IMPACT programme, the Mother buddies intervention was developed to augment the Focused Antenatal Care Model (Table 1). This four-visit antenatal care model is based on WHO clinical guidelines and was used to develop the Mother buddies interactions with pregnant women.

Table 2. Schedule and overview of Mother buddy visits.

\begin{tabular}{|c|c|c|c|c|c|c|c|c|}
\hline MB Visits & $\begin{array}{l}1 \text { Checking \& } \\
\text { Teaching }\end{array}$ & $\begin{array}{l}2 \text { Assessing the pregnant } \\
\text { woman }\end{array}$ & $\begin{array}{l}3 \text { Checking \& } \\
\text { Teaching } \\
\end{array}$ & 4 Checking & 5 Checking & $\begin{array}{l}6 \text { Checking } \\
\text { \& Teaching }\end{array}$ & 7 Checking & $\begin{array}{l}8 \text { Checking \& } \\
\text { Teaching }\end{array}$ \\
\hline \multirow[t]{2}{*}{ Gestation } & News of pregnancy & $5^{\text {th }}$ to $7^{\text {th }}$ month & $8^{\text {th }}$ to $9^{\text {th }}$ month & Within $24 \mathrm{hrs}$ & 3 days after & $\begin{array}{l}\text { Before } 7 \\
\text { days }\end{array}$ & 3 months & 6 months \\
\hline & Client details & ANC attendance & ANC attendance & Birth details & $\begin{array}{l}\text { Danger sign } \\
\text { details }\end{array}$ & $\begin{array}{l}\text { Danger sign } \\
\text { details }\end{array}$ & Infant check & Infant checks \\
\hline Checking & $\begin{array}{l}\text { Understanding } \\
\text { teachings- } \\
\text { Suspected areas of } \\
\text { vulnerability and } \\
\text { need for ANC } \\
\text { attendance. }\end{array}$ & $\begin{array}{l}\text { HIV and Syphilis } \\
\text { testings.Understanding } \\
\text { Danger signs of pregnancy } \\
\text { and Birth plans. Doctor's visit }\end{array}$ & $\begin{array}{l}\text { Danger signs of } \\
\text { pregnancy. Other } \\
\text { emergency plans } \\
\text { and means of } \\
\text { transportation }\end{array}$ & $\begin{array}{l}\text { Danger signs } \\
\text { revisited and } \\
\text { Breast } \\
\text { feeding } \\
\text { patterns }\end{array}$ & $\begin{array}{l}\text { Mother \& } \\
\text { baby checks } \\
\text { and Doctor's } \\
\text { visit }\end{array}$ & $\begin{array}{l}\text { Mother \& } \\
\text { baby checks } \\
\text { and Doctor's } \\
\text { visit }\end{array}$ & $\begin{array}{l}\text { Danger signs } \\
\text { check. HIV } \\
\text { test and } \\
\text { Baby's } \\
\text { weight. }\end{array}$ & $\begin{array}{l}\text { Infant checks. } \\
\text { Vaccinations and } \\
\text { Family planning } \\
\text { options for } \\
\text { parents. }\end{array}$ \\
\hline
\end{tabular}


Mother buddies were selected through written and oral interviews, and trained using PMTCT and Maternal and Child Health training modules, with refresher trainings and retraining, to give one-on-one support for vulnerable pregnant women and families in rural communities. Mother buddies used Mihope phones to provide one-to-one life-saving support to pregnant women and their families during pregnancy and 6 months after childbirth. Life-saving support included information on HIV, PPTCT, family planning, Sexually Transmitted Infections, increasing male partners involvement, Antiretroviral(ARVs), essential new mother care and early infant care, young child care and family health education. Educational topics included the importance of attending antenatal clinic before delivery, means of transportation, healthy diet patterns, partner testing for HIV and syphilis, malaria prophylaxis and prevention, birth planning, infant feeding, immunization, and practical skills in early recognition of danger signs of pregnancy and infancy, livelihood support, reminders to clients on ANC and hospital visits with funds to assist clients for clinic visits where necessary and giving birth in a professionally attended facility. It also included improvement of knowledge and change of behaviors about HIV disease, new born and child health community awareness.

Up to 8 Mother buddy visits(Table 2) were conducted and a proposed timeline was developed to augment the Focused Antenatal Care Model. Implementation of the Mother buddies intervention involved 15 mother buddies, 2 supervisors, a programmme coordinator and close interaction with the Faith Alive Foundation/Tearfund project team.

\subsection{Settings and Participants}

Table 3. Number of women recruited, delivered, HIV prevalence, PMTCT enrollment and location of IMPACT programme.

\begin{tabular}{|c|c|c|c|c|c|c|c|c|c|}
\hline & \multirow{2}{*}{ B } & \multirow{2}{*}{$\mathrm{C}$} & \multirow{2}{*}{ D } & $\mathbf{E}$ & \multirow{2}{*}{$\mathbf{F}$} & $\mathbf{G}$ & \multirow{2}{*}{$\mathbf{H}$} & \multirow{2}{*}{$\mathbf{I}$} & \multirow{2}{*}{$\mathbf{J}$} \\
\hline & & & & $\%$ & & $\%$ & & & \\
\hline 1 & 134 & 92 & 0 & 0 & 0 & 0 & $\mathrm{P}$ & JE & Boda \\
\hline 2 & 286 & 190 & 27 & 9 & 27 & 100 & $\mathrm{P}$ & BA & Mista Ali \\
\hline 3 & 147 & 88 & 7 & 5 & 7 & 100 & $\mathrm{~K}$ & JA & Kaninkon \\
\hline 4 & 115 & 93 & 5 & 4 & 4 & 80 & $\mathrm{P}$ & $\mathrm{JE}$ & New Fobur \\
\hline 5 & 57 & 41 & 2 & 4 & 2 & 100 & $\mathrm{P}$ & JE & Babawo \\
\hline 6 & 115 & 62 & 0 & 0 & 0 & 0 & $\mathrm{P}$ & $\mathrm{JE}$ & Kerker \\
\hline 7 & 100 & 48 & 1 & 1 & 1 & 100 & $\mathrm{P}$ & $\mathrm{JE}$ & Itili \\
\hline 8 & 163 & 73 & 4 & 2 & 4 & 100 & $\mathrm{P}$ & BA & Gurrum \\
\hline 9 & 170 & 134 & 5 & 3 & 4 & 80 & $\mathrm{P}$ & $\mathrm{BA}$ & FarinLamba \\
\hline 10 & 150 & 117 & 5 & 3 & 4 & 80 & $\mathrm{P}$ & BA & Saya \\
\hline 11 & 204 & 142 & 3 & 1 & 3 & 100 & $\mathrm{P}$ & BA & Zukkun \\
\hline 12 & 192 & 149 & 16 & 8 & 16 & 100 & $\mathrm{~K}$ & JA & Tudun Wada \\
\hline 13 & 207 & 165 & 20 & 10 & 20 & 100 & $\mathrm{~K}$ & JA & Amban \\
\hline $14^{*}$ & & & & 0 & & 0 & $\mathrm{~K}$ & JA & Angwan Bek \\
\hline 15 & 96 & 66 & 2 & 2 & 2 & 100 & $\mathrm{~K}$ & JA & Angwan Feri \\
\hline FAF & 2,136 & 1,460 & 97 & 5 & 94 & 97 & & & \\
\hline
\end{tabular}

A-Serial Numbers of mother buddies and Faith Alive Foundation's.

B-Number of clients recruited April 1st 2013-March 31st 2015.

C -Number of clients that have delivered as of 31 st March 2015.

D- Number of mothers testing positive for HIV of the number recruited.

E- HIV prevalence among mothers recruited.

F- Number of positive mothers that enrolled in PPTCT/PMTCT IMPACT programme.

G-\% OF Positive mothers that enrolled into PPTCT/PMTCT IMPACT programme.

$\mathrm{H}$-State.

I -Local Government.

J- Communities/Villages.

*-Project suspended.

P-Plateau State

K-Kaduna State

JE-Jos East Local Government of Plateau State

BA-Bassa Local Government of Plateau State

JA-Jamaa Local Government of Kaduna State

The Faith Alive Foundation Mother buddies intervention and IMPACT programme were implemented at 15 different communities and 3 local government areas of two states (Table 3). Faith Alive is a faith based non-profit organization established in 1996 and headquartered in Jos Nigeria providing holistic health, social and spiritual services to the less privileged especially Persons Living Positively at no cost to them. Antenatal Clinics are held twice weekly and women that visit with spouses are given preference on the queue and also special breakfast and gifts. This is one way of encouraging male involvement. A lot of educational activities and HCT are done. ANCs are also held in the community Primary Health Care (PHC) Centers and other government clinics/hospitals nearest to clients and "clinics" of TBAs.The programme provided outreach to vulnerable pregnant women, their children, male partners, and community members. Religious 
and community leaders along with mother buddies identified all pregnant women. Those who tested HIV positive in a protected confidentiality setting were enrolled into care, treatment and support at the various Faith Alive Hospitals and clinics nearest to them but mainly in Jos as well as PHCs/government clinics/hospitals most of whom were later referred to FAF for the free holistic medical care including access to the Faith Alive Necessities of Life (FANOL) Bank for food, clothing and shelter where necessary. The communities were selected based on poor access to health care and other need assessments conducted by the project team.

\subsection{Data Collection and Analysis.}

Demographic information were collated from Antenatal clinics of the PHCs, other government clinics and hospitals and also FAF rural clinics and in Jos especially in the various communities where the project was cited. Also used were clients' homes, community outreaches/awareness events, Mihope phones, questionnaires and interviews by trained volunteers/staff involved in implementation of the programme. Analysis included all pregnant mothers, male partners, neonates/infants, and community members who registered at the clinics. Each record was evaluated for evidence of HIV testing (mothers, male partners, infants), treatment with ARVs, PMTCT interventions, Mother buddy interactions and follow-up and documentation of infant feeding patterns.
Mothers served by the Mother buddy intervention were interviewed before commencement of project and after at Antenatal clinics or in their homes to assess the impact the intervention may have had on mother-to-child transmission and their knowledge of HIV disease and related issues.

\section{Results}

\subsection{Study Population}

A total of 2,138 vulnerable pregnant women were recruited and tested for HIV, syphilis, and hepatitis B infection. Ninety-seven pregnant women were HIV positive, and placed on Care, Treatment and Support. A total of 1,408 men accompanied their partners to antenatal clinic, and of this group, 1,402 had HIV testing performed. A total of 1,460 women delivered safely.

Of the $97 \mathrm{HIV}$-positive women, 64 gave birth safely and the babies received PPTCT/PMTCT interventions. Fortyseven babies tested negative to two DNA PCR tests at 6 weeks after delivery and 6 weeks after cessation of breast milk feeding, while 17 babies tested negative to first DNA PCR, and were awaiting second DNA PCR after 6 weeks of cessation of breast feeding at the time of this analysis (Table 4 and figure 2). The IMPACT programme reached 21,733 members of the various communities.

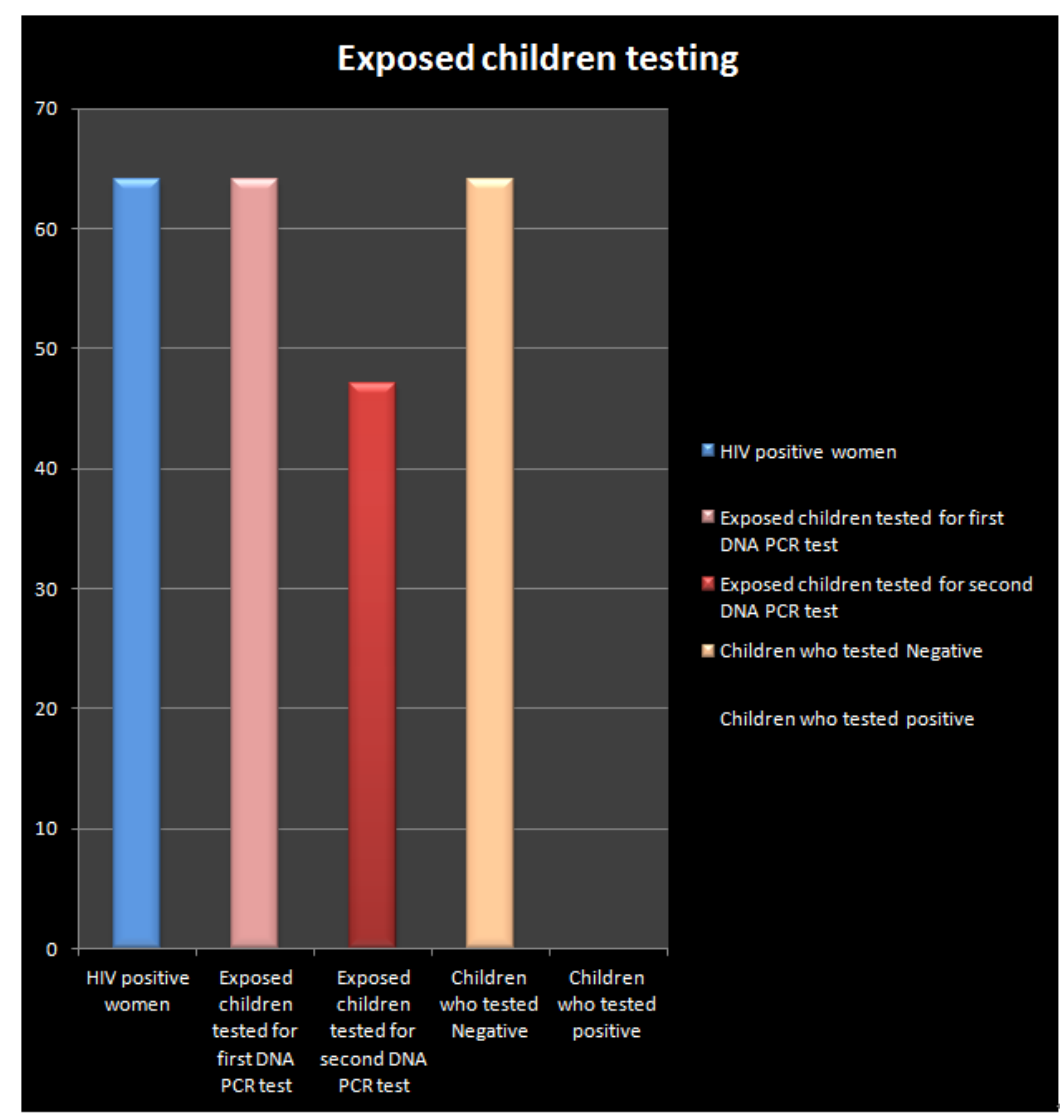

Figure 2. Postnatal HIV Testing of Children from HIV-positive mothers (DNA-PCR). 
Table 4. Postnatal HIV Testing of Children from HIV-positive mothers (DNA-PCR).

\begin{tabular}{ll}
\hline Indicator & \# of clients \\
\hline HIV positive women & 64 \\
Exposed children tested for first DNA PCR test & 64 \\
Exposed children tested for second DNA PCR test & 47 \\
Children who tested Negative & 64 \\
Children who tested positive & 0 \\
\hline
\end{tabular}

\subsection{Overall Impact of Mother Buddies Intervention}

Interviews and programme evaluation before and after the project found that Mother buddies were able to educate the community (men and women together) on the importance of antenatal clinics, hospital delivery and PPTCT. Mother buddies delivered needed education and up to 8 visits to vulnerable pregnant women from conception to 6 months post-partum.

This intervention improved attendance at 4 antenatal clinic visits, PPTCT, HIV counseling and Testing (HCT) for women and their male partners, hospital deliveries, and community awareness.

The Mother buddies' interactions were accomplished on a one-on-one basis, and seemed to increase knowledge, attitudes and practice of pregnant women involved in the IMPACT programme. It also promoted health seeking behavior and improved access and uptake for PMTCT services in these rural areas. The pilot studies in Malawi and Nigeria have proven that Mother buddies can be mobilized and trained to identify and support pregnant women and their male partners through the whole process of pregnancy until 6 months after birth.

\subsection{Lessons Learned}

The findings from the recent study drew attention to various successes and challenges of Tearfund partners' PPTCT programmes and can be useful guide to steering ongoing work. Motivating community involvement in PPTCT has been a challenge for many partners. Partners reported that men are often unwilling to be tested for HIV and tend to see pregnancy and child care as the sole responsibility of women hence the attempt for the key word of PPTCT rather than PMTCT. Furthermore, many health clinics do not keep adequate records on community and male involvement, so progress and trends in these areas are difficult to track and should be reversed.

Programme evaluation provided helpful feedback regarding programme effectiveness, impact and limitations. This should be encouraged.

MBs have improved community-clinic communication by linking pregnant mothers to clinics. The collated phone data compared to baseline suggests a great improvement in PPTCT services and programmes. Women who tested HIV positive were identified, enrolled into Care, Treatment and
Support and delivered in a health facility. Exposed infants got Post Exposure Prophylaxis(PEP) and cotrimoxazole (Cotrim/Bactrim) prophylaxis and all children born within this project period especially with the various interventions tested negative by DNA-PCR - prove that universal zero vertical transmission is possible as recently proven in the country of Cuba.

\section{Discussion}

Prevention of mother to child transmission of HIV begins with the non-pregnant woman. It is pertinent to note that before the intervention using mother buddies 70,000 infants were infected annually in Nigeria with HIV through vertical transmission, some of the reasons for this high figure are lack/inadequate HIV Counseling and testing, treatment, care and support, post exposure prophylaxis for exposed babies and appropriate infant feeding. The Mother buddies have helped by educating all women of childbearing age in these communities on how to remain HIV-negative, importance of early HIV testing and diagnosis in pregnancy and the risk of HIV transmission from mother-to-child which has been significantly reduced to near $0 \%$ as observed in this project though about $26 \%$ of babies born were still awaiting the second DNA-PCR results. In 2013 a two year baseline HIVMTCT rate was $3.2 \%$, reduced specifically to $2.1 \%$ and less in 2014. In 2013-2015 project year, it has been drastically improved upon to near $0 \%$. This is also in line with the national HIV prevalence trend currently at $3.4 \%$. This is encouraging and need to be sustained inspite of donor fatigue or systematic withdrawals by Internal donor agencies including PEPFAR. Sustainable funding and other support from all tiers of government and stakeholders is desired including embarking on various sustainable projects by stakeholders. Politcial commitment and stability along with need for a peaceful environment is necessary The success rate of the project can be attributed to the scalable and transferrable live saving skills of mother buddies who served as mentors, influencers, peer educators, mobilizers and key opinion leaders at the community level. However the following challenges need to be addressed to strengthen future interventions.

Firstly, the concept of Mother buddies should be expanded beyond faith based organizations to ensure that pregnant women and their male partners receive quality care from pregnancy to six months after birth and beyond, through interventions focusing on mother buddies involvement thereby reducing vertical transmission and encouraging community support to reduce loss to follow up in PPTCT and involvement in community HAART with a long-term goal of attaining or sustaining zero vertical transmission of HIV/AIDS.

Secondly, pregnant women in low- and middle-income countries are often unable to easily access antenatal and PPTCT services because of logistics (travel fees and time of antenatal clinics). Besides caring for their children they are expected to work hard preparing food, fetching water or tending crops. Many live a long way from their nearest health 
facility and have little access to transport. Between 2005 and 2011, nearly a third of pregnant women in South-East Asia, Eastern Mediterranean and African Regions did not attend an antenatal clinic. Women that do visit an antenatal clinic often only do so once during their pregnancy. This greatly reduces the number of women that can be reached by PPTCT programmes.To increase attendance; clinics should aim to be as accessible as possible. Improvements might include providing travel services or changing opening hours.

Thirdly, as many women still deliver at home, it is important to ensure that those who test positive for HIV have access to the necessary antiretroviral drug needed for PPTCT, including treatment for the neonate/infant in line with Option B + which recommends that all HIV-positive pregnant women are placed onto a triple antiretroviral regimen (HAART) for PPTCT, irrespective of their CD4 count, and continuing for life. This approach protects the health of the mother, whilst also reducing the risk of HIV transmission to her child and all future pregnancies. Using the same standard fixed-dose combination regimen for both PPTCT and first line treatment in adults, as recommended in Option $\mathrm{B}$ and $\mathrm{B}+$, enables a more efficient treatment supply-chain and task shifting with Trained Birth Attendants.

Fourthly, the goal of "Eliminating new HIV infections among children by 2015 and keeping their mothers alive" was launched by UNAIDS in 2011. Achieving the second half of this goal "keeping their mothers alive" relies on overcoming many of the barriers that also make implementing PPTCT services a challenge; fear and stigma of testing, difficulty accessing healthcare services, a need for integrated services particularly PPTCT and adult HIV treatment services. In addition to this, are difficulties expanding access to antiretroviral treatment to universal levels, such as, political commitment, lack of infrastructure and availability of funding. Also important, however, is the development of community support networks that provide care and support to women living with HIV. Mother buddies who are HIV positive and also take their ARVs provide adherence support to families living with HIV, sharing their own experiences and help to answer some questions they have and allay their fears, this also helps to reduce stigma and discrimination. Such MBs become role models to others.

Despite these challenges, scaling up this unique initiative will require a deeper understanding of the concept of mother buddies.

In other to scale and sustain this project in the communities more Mother buddies will have to be identified, trained, empowered and supported through a robust engagement in communities, towns and villages.

\section{Conclusion}

PPTCT is the window of opportunity available for an HIV free world, while women and children remain the bedrock of any nation or society. Health issues concerning them especially in the areas of reproductive health must be taken seriously.
Though some logistics challenges, security concerns and project design limitations were observed, "Mother buddies" have largely demonstrated capacity to increase access to PPTCT services, reduce vertical transmission of HIV, maternal and child deaths in hard to reach and underserved communities. Their intervention has largely changed health behavior and improved PMTCT programme outcomes and knowledge of HIV disease.

\section{Recommendations}

There is need for advocacy for the improvement and scaling up of PPTCT programmes especially with Nigeria having the least PMTCT indicators in Africa and addition of MBs to the team will be beneficial.

Scaling up the use of Mother Buddies in communities where it has been most effective and introducing it to communities where it is likely to have the greatest impact.

Adoption of the concept of Integrated Supportive Supervision trainings with integration of $\mathrm{MCH}$ into all levels of health care system.

Continuous sensitization and advocacy for male involvement in preventing parent to child transmission of HIV.

Formations of PPTCT support groups to help create awareness to reduce stigma and discrimination and provide support for pregnant women and their families.

\section{Acknowledgement}

Our appreciation to Dr Arthur Ammann of Global Strategies for HIV Prevention, California USA and Dr Hillary Lum of University of Colorado Anschutz Medical Campus, Colorado, USA, for guiding authors through this manuscript and also to Tearfund,UK/Souter Charity Foundation, UK for funding the project.

\section{References}

[1] Isichei Christian, Courtney Snelling Jennifer, Onwuezobe Caroline, Oyebode Tinuade, Mercy Isichei, Njab Jean et al (2015). A Novel Intervention to Increase Male Involvement in Prevention of Parent to Child Transmission of HIV. Science Journal of Clinical Medicine, 4(2):41-51.

[2] Christian O. Isichei, Arthur J.Ammann (2015). The role of Trained Birth Attendants in Delivering PMTCT Services. American Journal of Health Research 3(4):232-238

[3] Christian Isichei, Pamela Brown, Mercy Isichei, Jean Njab, Tinuade Oyebode, Prosper Okonkwo. (2015). HIV prevalence and associated risk factors among rural pregnant women in North Central Nigeria. American Journal of Health Research, $3(1): 18-23$.

[4] Dzama H, Deakin D Empowering "Mother Buddies" of pregnant mothers: lessons learnt from "grassroot communities" on the use of an android-based mobile phone system in the reduction of HIV and maternal mortality in Malawi-Poster Exhibition WEPE452 AIDS 2014, $20^{\mathrm{TH}}$ International AIDS Conference,Melbourne,Australia(July 20-25 ${ }^{\text {th }} 2014$ ) 
[5] WHO (2010) 'Guidelines on HIV and Infant Feeding 2010', Geneva; Friday, 1 January, 2010.

[6] WHO (2010) 'Antiretroviral drugs for treating pregnant women and preventing HIV infection in infants: Towards Universal Access', Geneva; Friday, 1 January, 2010

[7] WHO (1996) 'Maternity waiting homes: a review of experiences'.

[8] Tenthani et al (2014) ' Retention in care under universal antiretroviral therapy for HIV-infected pregnant and breastfeeding women ('Option B+') in Malawi' in Lippincott Williams \& Wilkins.

[9] Temmerman M. et al, "Mother-to-child HIV transmission in resource poor settings: how to improve coverage?", AIDS 17(8), 23 May 2003.

[10] Bulterys M. et al (26 January 2002), " Role of traditional birth attendants in preventing parental transmission of HIV", BMJ 324(7331).

[11] UNICEF (2008, July) ' Guidance on ensuring effective supply chain planning for commodities needed for implementation and scale up of services for the prevention of mother to child transmission PPTCT of HIV infection'

[12] Bassett M.T. (March 2002), ' Ensuring a Public Health Impact of Programs to Reduce HIV Transmission from Mothers to Infants: The Place of Voluntary Counseling and Testing', American Journal of Public Health 92(3)/

[13] Shetty A.K. et al (November 2005), ' The feasibility of voluntary counseling and HIV testing for pregnant women using community volunteers in Zimbabwe', Int J STD AIDS.

[14] Homsy et al (June 2006), ' Routine intrapartum HIV counseling and testing for prevention of mother-to-child transmission of HIV in a rural Ugandan hospital', JAIDS $42(2)$.

[15] CDC (26 November 2004), ' Introduction of Routine HIV Testing in Prenatal Care --- Botswana, 2004', MMWR 53(46).

[16] Wilfert C. (13 August 2006), ' Site Specific Factors Influencing Access to PPTCT Services, Trends with Time, and Suggestions for Improvement', XVI International AIDS Conference.

[17] Angotti N. et al (2011, July) ' An offer you can't refuse? Provider-initiated HIV testing in antenatal clinics in rural Malawi'.

[18] WHO (2011) ' Towards the elimination of mother-to-child transmission of HIV: Report of a WHO technical consultation (9-11 November 2010, Switzerland)'.

[19] Malonza I.M. et al (3 January 2003), " The effect of rapid HIV-1 testing on uptake of perinatal HIV-1 interventions: a randomized clinical trial", AIDS 17(1).

[20] Bulterys M. et al (28 February 2002), " Advances in the prevention of mother-to-child HIV-1 transmission: current issues, future challenges", AIDScience 2(4).

[21] Lu L et al (2009), " HIV incidence in pregnancy and in the first post-partum year and implications for PPTCT programs: Francistown, Botswana", CDC.
[22] UNAIDS (2012) ' Women Out Loud'.

[23] USAID (2 April 2003), "Women's Experiences with HIV Serodisclosure in Africa: Implications for VCT and PPTCT" [PDF].

[24] Mark J.Siedner et al A combination of SMS and transportation reimbursement intervention to improve HIV care following abnormal CD4 test results in rural Uganda, a prospective observational study,BMC Medicine 2015,13:160.

[25] Martin-Herz S.P. et al (December 2006) "Perceived risks and benefits of HIV testing, and predictors of acceptance of HIV counseling and testing among pregnant women in Zimbabwe", International Journal of STD \& AIDS 17(12).

[26] USAID (2 April 2003), " Women's Experiences with HIV Serodisclosure in Africa: Implications for VCT and PPTCT " [PDF].

[27] Medley A. et al (April 2004), " Rates, barriers and outcomes of HIV serostatus disclosure among women in developing countries: implications for prevention of mother-to-child transmission programmes", Bulletin of the World Health Organization 82(4).

[28] Semrau K. et al (24 March 2005), " Women in couples antenatal HIV counseling and testing are not more likely to report adverse social events", AIDS 19(6).

[29] Farquhar C. et al (15 December 2004), " Antenatal couple counseling increases uptake of interventions to prevent HIV-1 transmission", JAIDS 37(5).

[30] PlusNews (2012, January 16th) ' KENYA: The downside of male involvement in PPTCT'.

[31] Smart T. and Sheriff L. (14 July 2006), " Getting the most prevention and care out of programmes for the prevention of mother-to-child transmission", HATIP 70. "[PDF].

[32] De Paoli M. M. et al (May 2004), " Factors influencing acceptability of voluntary counseling and HIV-testing among pregnant women in Northern Tanzania", AIDS Care 16(4).

[33] UNAIDS (2011) ' Countdown to Zero: Global Plan Towards the Elimination of New HIV Infections Among Children By 2015 and Keeping Their Mothers Alive 2011-2015'.

[34] Linkages Project (14 April 2004), "A Review of UNICEF Experience with the Distribution of Free Infant Formula for Infants of HIV-Infected Mothers in Africa".

[35] All Africa (2010, 11th March), "Mothers' protest at withdrawal of free formula milk".

[36] Coutsoudis A. et al, " Free formula milk for infants of HIVinfected women: blessing or curse?", Health Policy and Planning 17(2), June 2002.

[37] WHO/UNAIDS/UNICEF (2010) 'Towards Universal Access: Scaling up priority HIV/AIDS interventions in the health sector', Geneva.

[38] UN News Centre (2010, 11th January)'UN seeks to virtually eliminate mother-to-child transmission of HIV/AIDS in Africa'. 